\title{
'Literatura antioqueña' en Ediciones ACADÉmicas de Rafael Montoya Y MONTOYA: LOS PROCESOS EDITORIALES Y SUS AGENTES EN LA DEFINICIÓN DE UNA TRADICIÓN LITERARIA*
}

\author{
'Antioquian Literature' in Ediciones \\ Académicas by Rafael Montoya y Montoya: \\ Editorial Processes and Their Agents in \\ the Definition of a Literary Tradition
}

\begin{abstract}
* Artículo derivado del trabajo de grado $L a$ literatura antioqueña en ediciones académicas de Rafael Montoya y Montoya (Medellin, 19581976): Recuperación editorial de una tradición literaria presentado para optar al título de Filólogo Hispanista de la Universidad de Antioquia.

Cómo citar este artículo: Salazar Echavarría, A. (2021). 'Literatura antioqueña' en Ediciones Académicas de Rafael Montoya y Montoya: los procesos editoriales y sus agentes en la definición de una tradición literaria. Estudios de Literatura Colombiana 49, pp. 87-104. DOI: https://doi.org/10.17533/udea.elc.n49a05

1 https://orcid.org/ 0000-0002-9103-3056 alexander.salazare@udea.edu.co Universidad de Antioquia, Colombia
\end{abstract}

Editores: Andrés Vergara Aguirre, Christian Benavides Martínez

Recibido: 15.02 .2021

Aprobado: 21.05.2021

Publicado: 30.06 .2021

Copyright: (92021 Estudios de Literatura Colombiana. Este es un artículo de acceso abierto distribuido bajo los términos de la Licencia Creative Commons AtribuciónNo comercial-Compartir igual 4.0 Internacional

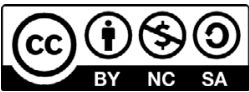

\section{Alexander Salazar Echavarría ${ }^{1}$}

Resumen: Se propone una definición de "literatura antioqueña” a partir de la colección Ediciones Académicas. Para ello se analiza la manera en que los procesos editoriales (recolección bibliográfica, reedición de textos, diseño, críticas a la edición o a sus autores, entre otros) intervienen en la producción y circulación de una "literatura regional". Dicho concepto será entendido como una tradición literaria que sobrevive en el tiempo, en cuanto idea, gracias a la aplicación de estrategias editoriales y al trabajo de diversos agentes, entre ellos el editor, que se encarga de producir una nueva obra a partir de textos ya publicados y dispersos.

Palabras clave: Ediciones Académicas; Rafael Montoya y Montoya; edición en Colombia; literatura antioqueña; tradición literaria.

Abstract: A definition of "Antioquian literature" is proposed based on the Ediciones Académicas collection. To this end, we analyze the way in which editorial processes (bibliographic research, reprinting of texts, design, criticism of the edition or its authors, among others) intervene in the production and circulation of a "regional literature". This concept will be understood as a literary tradition that survives over time, as an idea, thanks to the application of editorial strategies and the work of various agents, including the editor, who is responsible for producing a new work from already published and dispersed texts.

Keywords: Ediciones Académicas; Rafael Montoya y Montoya; Colombian Publishing, Antioquian literature; Literary Tradition. 


\section{Introducción}

Ediciones Académicas fue un proyecto editorial desarrollado en Medellín por Rafael Montoya y Montoya (Rionegro, ¿? - Bogotá, 1982) entre los años 1958 y 1976. Montoya y Montoya fue educador, editor y empresario. De su faceta como educador se conocen sus labores en el Colegio Académico de Antioquia, institución de la que fue rector durante sus primeros años. Dentro del mundo empresarial, fue socio fundador de la Cooperativa de Impresores y papeleros de Antioquia (Coimpresores), y allí ocupó cargos administrativos en varias ocasiones.

Los tomos de Ediciones Académicas se publicaron en un primer momento en los Talleres gráficos de la Editorial Bedout y luego en los Talleres gráficos de la Editorial Montoya. El editor publicó obras completas, obras individuales, novelas y antologías de diversos géneros: cartas, cuentos, poesía, ensayo. Los autores eran por lo general colombianos y excepcionalmente extranjeros. La empresa se propuso la recuperación de una "tradición literaria", concepto que discutiremos más adelante.

No hemos logrado establecer con claridad a qué hace referencia exactamente el nombre de "Ediciones Académicas". Los prólogos a las ediciones y demás paratextos hacen pensar en una alusión, en todo caso nunca estricta, a la edición de textos literarios con rigor filológico, esto es, sustentados en la amplia recuperación bibliográfica, el establecimiento de un texto fiable y el aporte desde la crítica legitimada. Sin embargo, ese carácter "académico" de las ediciones, al que el editor da importancia en repetidas ocasiones, no debe confundirse con los parámetros actuales de la edición crítica de textos literarios modernos.

Para el análisis tendremos como corpus aquellos tomos de la colección dedicados a autores antioqueños (ver tabla 1). Sin embargo, por cuestiones de espacio, nos centraremos en los textos referentes a dos autores: Juan de Dios Uribe y Gregorio Gutiérrez González, sin que esta circunstancia implique el abandono del diálogo con el corpus total.

Los tomos se publicaron en tres formatos y diseños diferentes: una edición de lujo para suscriptores y dos ediciones en rústica. En este trabajo nos centraremos en la edición de lujo, porque es allí en donde se registra una mayor intervención editorial. Este formato es de $17 \times 12 \mathrm{~cm}$, tiene una funda de tela roja y cartulina blanca con ilustraciones a color que incluyen en la cara anterior el nombre del autor, el título de la obra y un motivo alusivo, y en la cara posterior presentan el próximo título de la 
colección, así como información de contacto. La cubierta es de cuerina roja (ver figura 1). Las guardas presentan el motivo de una mazorca con el nombre del sello editorial (ver figura 2). En el interior de los tomos se incluyen anexos entre fotografías, facsimilares y una lista de suscriptores habituales.

Tabla 1. Corpus. La literatura antioqueña en Ediciones académicas

\begin{tabular}{|c|c|c|c|c|c|c|}
\hline $\begin{array}{c}\text { Año de } \\
\text { publicación }\end{array}$ & $\begin{array}{c}\text { Año de } \\
\text { reimpresión }\end{array}$ & Vol. & Título & Autor & $\begin{array}{c}\text { Población } \\
\text { de origen }\end{array}$ & Imprenta \\
\hline 1958 & $\begin{array}{c}1959(2), \\
1960\end{array}$ & 1 & Obras Completas & $\begin{array}{c}\text { Gregorio Gutiérrez } \\
\text { González }\end{array}$ & $\begin{array}{c}\text { La Ceja del } \\
\text { Tambo }\end{array}$ & Bedout \\
\hline 1960 & 5 & Obras Completas & Epifanio Mejía & Yarumal & Bedout \\
\hline 1961 & 6 & Obras Completas & José Félix Restrepo & Envigado & Bedout \\
\hline 1961 & 1970,1971 & 7 & Obras Completas & $\begin{array}{c}\text { Camilo Antonio } \\
\text { Echeverri }\end{array}$ & Medellín & $\begin{array}{c}\text { Editorial } \\
\text { Montoya }\end{array}$ \\
\hline 1962 & 8 & Obras Completas & Porfirio Barba Jacob & $\begin{array}{c}\text { Santa Rosa } \\
\text { de Osos }\end{array}$ & $\begin{array}{c}\text { Editorial } \\
\text { Montoya }\end{array}$ \\
\hline 1963 & 10 & $\begin{array}{c}\text { Oraciones } \\
\text { Panegíricas }\end{array}$ & Luis López de Mesa & Donmatías & Bedout \\
\hline 1965 & 12 & Cogitaciones & Luis López de Mesa & Donmatías & $\begin{array}{c}\text { Editorial } \\
\text { Montoya }\end{array}$ \\
\hline 1965 & 1976 & 21 & $\begin{array}{c}\text { Obras Completas } \\
\text { (primer tomo) }\end{array}$ & Juan de Dios Uribe & Andes & $\begin{array}{c}\text { Editorial } \\
\text { Montoya }\end{array}$ \\
\hline 1965 & 14 & $\begin{array}{c}\text { Obras Completas } \\
\text { (segundo tomo) }\end{array}$ & Juan de Dios Uribe & Andes & $\begin{array}{c}\text { Editorial } \\
\text { Montoya }\end{array}$ \\
\hline 1965 & 15 & $\begin{array}{c}\text { Obras Completas } \\
\text { tercer tomo) }\end{array}$ & Juan de Dios Uribe & Andes & $\begin{array}{c}\text { Editorial } \\
\text { Montoya }\end{array}$ \\
\hline 1968 & & Tomás Carrasquilla & $\begin{array}{c}\text { Santo } \\
\text { Domingo }\end{array}$ & $\begin{array}{c}\text { Editorial } \\
\text { Montoya }\end{array}$ \\
\hline
\end{tabular}

Fuente: elaboración propia

Los anexos tenían el propósito de brindar un contexto del autor editado y eran obra de escritores de renombre con poder de legitimación. Por lo general los textos ya habían sido publicados en otros medios y en muchos casos los autores habían fallecido para el momento en que Montoya y Montoya los reeditó. Esta circunstancia obliga a un énfasis en el matiz autoral que adquiere el editor, puesto que este les da a los materiales un nuevo significado al aglutinarlos dentro de una colección y un tomo en específico. Se trata de un proceso de "mutación” en el que las piezas individuales dispersas en la prensa se inscriben en un corpus y donde, por tanto, su sentido se halla “contaminado por la proximidad" de otras piezas (Chartier, 1994, p. 47).

Pero antes de revisar los anexos, es necesaria una discusión de la idea de tradición literaria que sirva como marco referencial de la lectura que proponemos. 


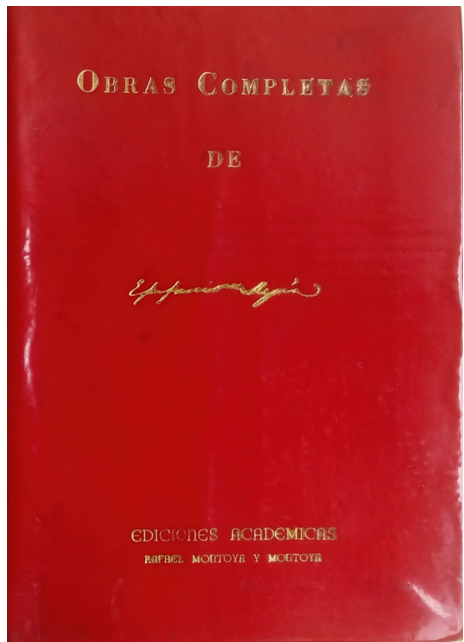

Figura 1. Cubierta de Obras Completas de Epifanio Mejia

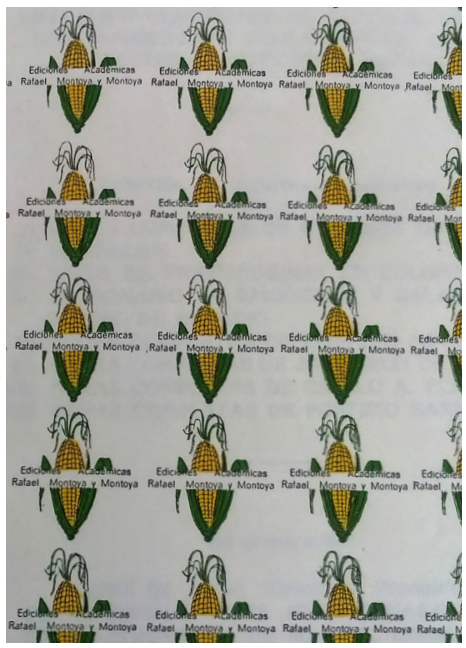

Figura 2. Guardas edición de lujo

\section{Tradición literaria como categoría de Análisis}

La idea de una literatura nacional está vinculada a la formación de los Estado-nación modernos (Janik, 1998, pp. 7-8). Esta se expuso y discutió dentro de espacios de sociabilidad, y se difundió a través de publicaciones periódicas, antologías, prólogos, etc. (Vasco Acosta, 2016, pp. 6-12). El “canon” que surgió de esta circulación de las ideas pasó a considerarse a lo largo del siglo xx como patrimonio nacional que debía recuperarse. La problematización comienza una vez se deja de admitir sin reservas la acepción de que el canon constituye lo más representativo de una nación y se lo define como discurso de élite, esto es, algo que no es inamovible y eterno, sino arbitrario. Si se lo traspone al caso colombiano: el canon de la literatura colombiana representa a hombres blancos, católicos, heterosexuales, que escriben en español y que se consideran herederos de la cultura occidental, que es, a su vez, una cultura superior a las demás.

El cuestionamiento de la idea de "canon" ha sido posible por el reconocimiento de procesos externos, periféricos, a la obra literaria. En esta discusión se ha optado por la interdisciplinariedad y se ha reconocido el valor de los instrumentos y modelos de la historia, la sociología, la antropología, la lingüística, entre otras ramas, para darle un significado más preciso a la literatura.

Algunas investigaciones recientes han cuestionado el corpus que conforma la denominada "literatura colombiana". Los estudios editoriales, para no ir muy lejos, 
son un buen ejemplo. Al cambiar el foco de atención de las obras "más representativas" de la literatura colombiana, que es una idea alrededor del canon, y centrarse en la producción de una editorial determinada, estos estudios aportan a la "bibliodiversidad" y amplían con ello el espectro de lo que se entiende por literatura. También podríamos hablar de los estudios de género o los estudios étnicos. Los alcances de este artículo no permiten realizar una discusión amplia con las investigaciones a las que hacemos referencia en este punto. Nos limitamos, por lo tanto, a indicar un par de ejemplos recientes. Ana María Agudelo Ochoa (2015) inicia su estudio sobre las escritoras Josefa Acevedo de Gómez y Soledad Acosta de Samper, afirmando que

[...] los grupos femeninos en Colombia desde el inicio de su historia social han contado con no pocas trabas para el desarrollo de su especificidad. Excluidas de la vida pública, sometidas a los dictámenes de la férrea y jerarquizada sociedad a la que pertenecen y relegadas a las actividades propias del ámbito de lo privado, las mujeres colombianas de la era decimonónica contaron, hasta bien entrado el siglo xx, con muy pocas opciones de realización personal (p. I).

Para el caso de las culturas indígenas, Selnich Vivas Hurtado (2015), en su estudio de la poesía minitka, señala que, "torpemente, la vergüenza étnica que heredamos del modelo colonialista nos impide sentir interés por cualquier cultura que no sea eurocéntrica, letrada. Mejor sentirnos europeos que descubrir una gota de indígena o de afro en casa” (p. 18). Entre los argumentos más recurrentes de este tipo de trabajos está la arbitrariedad de dicho corpus, que no representa la diversidad cultural del país. Este cuestionamiento ha dado con intentos diversos de incluir dentro de las expresiones de la literatura colombiana aquellos discursos no hegemónicos. Tal inclusión fracturó la idea de canon al dejar en evidencia su carácter excluyente e ideológico.

La necesidad de focalizar de manera diferente los procesos literarios es la justificación de optar por una editorial como objeto de investigación. Ahora bien, esta propuesta no debe asumirse en detrimento de los estudios literarios de mayor trayectoria, sino que apela a instrumentos diversos con los que se pretende criticar procesos que, aunque intervienen en lo literario, en ocasiones son dejados de lado en favor de la obra misma.

Al hablar de "tradición literaria" para referimos a lo que usualmente se conoce por "literatura colombiana", "literatura antioqueña” o, de manera más general, "literatura regional”, pretendemos evitar la argumentación dentro de presupuestos canónicos y, por el contrario, ver en el canon una variable más dentro de la complejidad de 
los procesos literarios, sobre todo aquellos que se refieren a los mecanismos de legitimación y conservación de los discursos. "Tradición literaria” abarca la idea de canon en cuanto producto de élite y permite entender la literatura en tanto conjunción de múltiples discursos.

El editor Rafael Montoya y Montoya es receptor de una tradición literaria y le da la consideración de patrimonio regional al ofrecerla como aporte en la definición de identidad de la nación. Pero hay que tener cuidado a la hora de establecer un juicio demasiado drástico y a priori frente a esta editorial, porque dicho juicio podría estar motivado por revaluaciones que se dieron décadas después. En los años sesenta la "ciudad letrada" y sus mecanismos de legitimación vinculados al poder no habían caído aún bajo el manto de la sospecha, por lo que Ediciones Académicas no debe tomarse como reacción frente a una suerte de legitimidades emergentes. Lo cual no significa que la producción editorial no estuviese reaccionando a algo. Gilberto Loaiza Cano (2016) ha señalado que en Colombia, a partir de la segunda mitad del siglo $\mathrm{xx}$, el monopolio indiscutido del libro como soporte de la cultura legítima comenzó a desmoronarse con la aparición de los medios de comunicación masiva: la radio y la televisión. De hecho, el abandono del libro por nuevos soportes ya era motivo de reservas y hasta reproches en el medio editorial en el que se movió Montoya y Montoya. El editor Benigno Gutiérrez, quien influyó profundamente en la labor de Montoya y Montoya, señalaba en 1956, refiriéndose a su "amada Antioquia", que estaba "embrutecida por la radio y el deporte y contagiada ya de un estúpido e incontrolable pragmatismo" (Gutiérrez Panesso y Levy, 1989, p. 57).También hay que tener en cuenta la emergencia de cierto nacionalismo en la producción editorial que se dio en la época y que pudo responder, entre otros factores, a la superioridad editorial de otras naciones de habla hispana, entre ellas Argentina, Chile, México, o la misma España, que impactó el mercado del libro en Colombia.

\section{La tradición literaria y los agentes dentro del circuito de circulación de las ideas}

Para entender las particularidades que introduce Ediciones Académicas al editar textos de una tradición decimonónica, nos centraremos en los procesos de recepción de las ideas. Partimos de la premisa básica de Roger Chartier (1994) de que "no hay texto fuera del soporte que lo da a leer, que no hay comprensión de un escrito, cualquiera 
que sea, que no dependa de las formas en las que alcanza a su lector"(p. 46). La comprensión de las ideas literarias necesariamente está unida a la compresión del soporte, y lo mismo sucede con los procesos de recepción. Al hacer referencia a esta, Horacio Tarcus (2016) distingue cuatro "momentos" dentro del "proceso global de producción y circulación de las ideas": producción, difusión, recepción y apropiación (pp. 72-78). Hablamos entonces de un momento de producción de una tradición literaria, pongamos de ejemplo la habitualmente denominada "literatura antioqueña", al referirnos a la "elaboración" del conjunto de ideas que la conforman. Lo sigue un momento de difusión de tales ideas a través de soportes, entre ellos las publicaciones periódicas y los libros, y de espacios de sociabilidad como las sociedades literarias. En tercer lugar, estaría un momento de recepción que nos ubica en los procesos de "adaptación" de la tradición, en la recuperación bibliográfica y la reedición de los textos, a través de “operaciones de selección y marcación”. Esta labor la llevan a cabo diversos agentes, entre ellos los editores, prologuistas y críticos. En último lugar estaría un momento de apropiación, que se refiere al "lector final" al "término de la cadena de circulación", que serían los lectores de las Ediciones Académicas, de los que nos llega noticia a través de las listas de suscriptores y las reseñas que aparecieron en publicaciones periódicas. Este circuito, ya se habrá notado, es artificial y, por tanto, sus momentos no deben tomarse como independientes y consecutivos. La producción de las ideas es también apropiación y recepción. La élite decimonónica antioqueña no produjo su literatura a partir de la nada, sino que esta surgió de la apropiación (lectura) y recepción (adaptación) de corrientes y movimientos extranjeros —el realismo, el naturalismo y el modernismo-, o de parámetros de definición de la cultura — las ideas de progreso y civilización- (Escobar Villegas, 2009, pp. 17-25). Por otra parte, la difusión difícilmente puede entenderse separada de la producción: la producción de la idea de literatura antioqueña fue un proceso en sí mismo, que no se redujo a la redacción de un manuscrito, digamos la escritura de Frutos de mi Tierra por Tomás Carrasquilla, sino que implicó discusión, crítica y continuas reelaboraciones estéticas en sociedades literarias y publicaciones periódicas (Vasco Acosta, 2016, pp. 6-12). La recepción a su vez trae implícita la noción de apropiación. Los agentes que en la década del cincuenta se preocuparon por la literatura antioqueña (Rafael Montoya y Montoya, Benigno A. Gutiérrez, Ediciones Togilber, Editorial Bedout, entre otros) partieron de una apropiación de dicha tradición a la hora de decidirse por adaptarla al nuevo público 
y reeditarla. En este circuito, del que depende la supervivencia de las ideas estéticas, los agentes ocupan un lugar principal. En el caso de Ediciones Académicas, el editor es el encargado de configurar la idea de literatura antioqueña, por cuanto produce el soporte que hace posible la circulación de dicha tradición.

Rafael Montoya y Montoya casi nunca estableció relaciones editoriales con autores vivos - lo que no lo eximió de recurrir a los herederos para contar con los derechos patrimoniales - Esta particularidad circunscribe su labor a la recopilación de fuentes dispersas, que se traduce en la voluntad de generar un imaginario de obra adjunto a un autor específico. De este modo, el editor amplía su espectro de labores, por lo general limitado a la dirección de la producción material del libro y los procesos de adecuación del manuscrito, para ocuparse además de otras tareas.

En las Obras Completas de Gregorio Gutiérrez González se incluye una "Nota sobre el editor”. En esta, León Zafir (seudónimo del poeta anoriceño Pablo Emilio Restrepo López) presenta a Montoya y Montoya haciendo especial énfasis en la importancia de su labor de editor para la cultura de Antioquia. Dice Zafir (1960) con evidente tono laudatorio:

Brioso como un venado calentano, ni estirado con ínfulas de gran publicista, ni encogido con maliciosa barraganería, se ha dado a la tarea que verdaderamente lo enaltece de rebujar archivos históricos, notarías, bibliotecas; visitar algunas poblaciones del Oriente antioqueño, hablar con viejos memoriosos, visitar en la Ceja del Tambo la casa solariega de "El Puesto" en donde nació Gregorio en el año de 1826 , el templo colonial donde fué bautizado y donde reposan los restos del poeta, arrodillarse a orar y a observar frente al altar del mismo templo la Pila de agua bendita en donde recibió las aguas bautismales el egregio y delicado cantor de Aures y de Julia y del Cultivo del Maíz y de todas las faenas labriegas; enderezar sus pasos voluntariosos hacia Sonsón por ir a conocer la casa que ocupó el bardo, deteniéndose a meditar en la mitad del puente desde donde "las aguas de Aures descender se ven"; recoger fotografías de todos estos lugares, de templos y de placas conmemorativas y retratos y autógrafos del poeta y hasta una foto de la Pila bautismal; escribir cartas, muchas cartas a los académicos que por lo general viven en Bogotá ( $\mathrm{y}$ en la luna) y con el acopio de todos estos datos y material poético, ponerse al frente de los operarios de los Talleres de Bedout, con una alegría casi infantil y un generoso anhelo de hacer labor cultural y revaluadora de los positivos gonfaloneros de la espiritualidad antioqueña, hasta entregarnos las obras completas de nuestro poeta eglógico en una bella edición que envidiarían las mejores casas editoras de América... iTal es la hazaña que ha realizado Rafael Montoya y Montoya, con una voluntad de acero colado! (pp. 455-45\%).

Hablamos de una labor de búsqueda bibliográfica que tiene por objetivo la reconstrucción de la figura del autor y su obra, para finalmente, con todo el material recuperado y analizado, intentar un discurso coherente, enlazado por el rótulo de "obras completas”, en el que se incluyan todos estos materiales que de cierta manera coaccionan el sentido de los textos. 
Sin embargo, la actitud de recuperación completa de los escritos de determinado autor, que no sigue parámetros de selección que superen el de autoría, no siempre fue recibida con entusiasmo. El poeta Helcías Martán Góngora (1964), en una reseña publicada en el Boletín Cultural y Bibliográfico del Banco de la República, escribe:

Pregunto, ahora, ¿̇i hay razón alguna para que un editor póstumo, lleno de buenas intenciones, incluya en las “Obras Completas", los poemas desconocidos, que Barba repudió públicamente? La respuesta negativa la dio en vida, el colérico Main Ximénez, anticipándose a tan ímproba labor de arqueología literaria. [...] Con la reimpresión de estos "Poemas desconocidos", muy poco o nada gana la gloria indeficiente de Porfirio Barba Jacob, en su designio intemporal (pp. 224I-2243).

Se exige, en este caso, que el editor no sea únicamente el agente que decide a quién debe publicarse, sino además qué, dentro de la variada producción de un autor.

El escenario en que el editor construye una obra — no se limita a editarla o reimprimirla - trae a primer plano su labor, esto es, lo visibiliza. Ahora bien, Montoya y Montoya llevó a cabo una empresa privada que fue financiada con capital propio y que no contó, hasta donde tenemos noticia, con apoyo de entidades gubernamentales o de políticas culturales. El tema de la falta de apoyo institucional para una empresa que pretendía impactar positivamente en los imaginarios regionales y nacionales, con un marcado énfasis en la cultura autóctona como identidad, será una constante en la sección que recoge las opiniones de personajes de renombre en el campo cultural del momento, titulada “Conceptos estimulantes para 'Ediciones Académicas", que se incluía en la parte final de los tomos.

El editor entonces utiliza su producción editorial no solo para generar un imaginario de autor, sino que además se vale de las páginas preliminares y anexos para construir una imagen de sí mismo. Entre estos se cuentan también las fotografías del editor, los conceptos positivos sobre su labor, la inclusión de su nombre dentro de las ediciones, sus prólogos y notas al pie. El objetivo final es vincularse como agente a la tradición literaria decimonónica denominada "literatura antioqueña" o, si hablamos de toda la colección en tanto conjunto, "literatura nacional".

Por su parte, consideramos que los suscriptores, en cuanto grupo definido de lectores, reciben y a la vez legitiman cierto "imaginario identitario" que se venía formando dentro de los círculos de las élites intelectuales de Antioquia desde el siglo anterior. Tal cual lo explica Escobar Villegas (2009), “antioqueño” tiene diversas acepciones: gentilicio — “naturales de un espacio administrativo que se llama Antioquia” (p. 284)—, punto de vista cultural — “una visión antropológica de la noción” (p. 285)—, o imaginario; esto es: 
Un conjunto de imágenes mentales que pretende adjudicar a todos los habitantes, -incluyendo los naturales y los por adopción-, de una región más o menos imprecisa y que no coincide siempre con las divisiones territoriales administrativas, una serie de características que los homologa, los define ante el mundo, los clasifica y los compara con otros imaginarios de identidad. Dicho conjunto de imágenes mentales fácilmente origina ideologías regionalistas, algunas veces con grandes dosis de agresividad, pero siempre con la idea clara de separarse de los otros (p. 286).

Este imaginario que definía lo "antioqueño" a partir de aspectos genéticos, geográficos y raciales permeó profundamente los discursos literarios, científicos, políticos y artísticos de la época. Ediciones Académicas es heredera de esa tradición no solo porque recuperó buena parte de sus figuras “heroicas", sino además porque los presentó al lector a través de los anexos críticos, en los que se propendía precisamente a la heroización y singularización de la figura del antioqueño, basada en la exaltación biográfica, los adjetivos rimbombantes y la vinculación de un individuo a una suerte de "percepción histórica de Antioquia". Elementos que responden, para decirlo con Escobar Villegas (2009), a los "mecanismos de la lisonja": "vanagloriar a los hombres y mujeres por el sólo hecho de pertenecer a la propia tierra de quien comenta, o porque quien escribe es un invitado de honor en la región de la cual proviene el biografiado" (p. 174).

La labor editorial se entiende, entonces, como recuperación de un "imaginario de identidad" que tiene un público objetivo bien definido: en el caso de las ediciones de lujo, tal cual lo evidencian las listas de suscriptores, se trata predominantemente de un lector masculino de élite y de instituciones principalmente educativas.

\section{La literatura antioqueña en Ediciones Académicas}

En este apartado trataremos de construir una definición de literatura antioqueña a partir del proyecto de Ediciones Académicas. La definición será necesariamente ambigua, llena de matices e incluso contradictoria, puesto que está compuesta de discursos elaborados por personajes disímiles, de épocas e ideologías diferentes. Sin embargo, a pesar de las distancias, creemos que hay unas líneas generales en las que los autores se apoyan para sustentar las tesis. Se dan comparaciones con otras regiones, se recurre a la autoridad legitimada, a la delimitación de una idea de "antioqueño" desde presupuestos culturales, raciales y geográficos, y a la búsqueda de lo universal en lo particular, que valida el uso de tipos regionales. A continuación, revisaremos cada una de estas líneas más detenidamente. 
La literatura antioqueña cuenta con figuras paradigmáticas, "bardos". Aquí nos referiremos principalmente a Juan de Dios Uribe y Gregorio Gutiérrez González. El primero, un liberal radical, conocido sobre todo por ser un escritor político, de estilo agresivo, con dominio de la sátira y de la apología, cuyo uso dependía del personaje reseñado. No es el gran poeta de la región, tampoco el gran novelista. Esos puestos se los han otorgado respectivamente a Gutiérrez González y Epifanio Mejía, en la primera categoría, y a Carrasquilla, en la segunda. Su inclusión es pertinente por su filiación política, en una región especialmente conservadora, y por los géneros en que se desenvolvió, que podríamos llamar menores en el sentido de que no contaban con el prestigio de la poesía y la novela. Gutiérrez González, por su parte, es el autor de uno de los textos paradigmáticos de lo que entendemos por literatura antioqueña: Memoria sobre el cultivo del maiz en Antioquia. Considerado repetidamente como el poeta de Antioquia, tenía una filiación política opuesta a la de Uribe. Estos ejemplos permiten percibir una idea de literatura regional que trasciende los límites de otro tipo de categorías ideológicas, como la de partidismo.

La discusión de si estos autores merecen o no el lugar en el que aquí, concisamente, los ubicamos carece de relevancia. Lo que importa en este apartado no es la selección de las figuras principales de la literatura antioqueña, o si tales figuras merecen el lugar que la tradición les ha otorgado, porque con ello caeríamos en las determinaciones canónicas que tratamos de evitar. Proponemos, en cambio, la revisión de la crítica que los autores han recibido y con ello aportar a la comprensión de los procesos de legitimación que culminan en la enunciación de un canon.

La definición de literatura antioqueña a partir de la colección Ediciones Académicas debe entenderse en el marco de un proyecto de carácter patrimonial más que político-sectario. Tal afirmación se sustenta en dos circunstancias. En primer lugar, la declaración de intención de la colección, que aparece en los prólogos del editor y en la publicidad de los medios impresos y radiales, nunca se refiere a un proyecto político, como lo podría ser, por poner el ejemplo más célebre, el de una Antioquia Federal. En cambio, sí es explícito y frecuente el propósito de recuperar el patrimonio que, aunque se identifica de manera regional, pretende tener un impacto nacional e internacional. En segundo lugar, porque la colección en sí presenta cierta heterogeneidad, pues no publica únicamente a autores antioqueños, sino también a autores de otras regiones y países. 
En línea con la tesis anterior, la literatura antioqueña se define a través del contraste con otras regiones y contextos. Es frecuente la comparación de los autores antioqueños con escritores de otras latitudes, en ocasiones resaltando la superioridad de lo antioqueño. Tomás Carrasquilla (1965), por ejemplo, en su prólogo a las Obras Completas de Juan de Dios Uribe anota:

Picón el aristócrata, Emilia la gallarda, Ricardo León el de las músicas, Bécquer el divino, se me hacen pálidos junto a este Petronio del prosal. Alguien le ha comparado a Montalvo, poniéndole debajo de este autor. iOh santa libertad de opinar! No existieras, y fuera a la pira quien tal afirmara. Montalvo, el de los perendengues rebuscados, el de los muestrarios gramaticales, el acervantado que pierde su personalidad, ¿̇superior a Juancho Uribe? (p. g).

También los autores extranjeros se valen de esta estrategia, como lo hace el español Juan Valera, quien en el apartado que Montoya y Montoya incluye al final de las Obras Completas de Gregorio Gutiérrez González —en el que el editor compila fragmentos de diversos autores - y que se titula "Gregorio Gutiérrez González ante la crítica universal", compara a este con el poeta latino Virgilio: "En las montañas antioqueñas suspiró con inefable melodía las estrofas de Gregorio Gutiérrez González, autor de las Geórgicas Colombianas, o hablando con más propiedad, antioqueñas" (Valera, 1960, p. 79).

La colección sustenta su legitimidad en dos aspectos principales. Por una parte, el diseño cuidado de la colección, que resalta la importancia canónica del editado. Por otra parte, el carácter "académico", entendido como rigor — en cuanto pretende establecer un texto fiable-, documentación prolija —en cuanto recoge anexos que permiten una contextualización biográfica del autor - y respaldo de autoridades que publican conceptos favorables o "estimulantes" frente a la colección o sus autores.

Las autoridades que respaldan la edición tienen un peso de legitimación. Uno de los textos de Tomás Carrasquilla, por ejemplo, es fragmentado en tres partes y publicado en tomos diferentes. El texto se publicó originalmente en El correo liberal el 6 de agosto de 1913 bajo el título de "Tres nombres", con el que se hacía referencia a Gregorio Gutiérrez, Epifanio Mejía y Juan de Dios Uribe. La división es problemática por cuanto Montoya y Montoya no cita la fuente original, no informa que se trata de un fragmento, pone a estos un título diferente en cada caso y excluye algunos apartados del original. Evidencias todas de un interés por el peso del nombre del prologuista por encima, incluso, de la coherencia del discurso. Lo importante es la reproducción de los fragmentos en los que se hace más evidente el respaldo de la 
autoridad frente al editado. Así, refiriéndose a Juan de Dios Uribe, el fragmento de Carrasquilla (1965) inicia:

¡El Indio!... “iDe pie para cantarla que es la patria!” iEste hombre! iYo no sé qué será este hombre! Espíritu celeste o satánico, es lo cierto que a mí me fascina y me embruja. No será un genio, tal vez ni un pensador; pero en eso de revelarse por medio de la forma, se me antoja que nadie le supera en nuestra lengua (p.9).

Lo “antioqueño” se define desde diversos parámetros. El principal es el geográfico. Antioqueño es el que nace en "Antioquia"; pero no una de realidades y límites geográficos, sino aquella que viene de los imaginarios decimonónicos. José María Vargas Vila (1965), por ejemplo, en un texto que se incluye a modo de prólogo en las Obras Completas de Juan de Dios Uribe, introduce una suerte de determinismo geográfico como explicación de las condiciones de posibilidad del artista. El texto de Vargas Vila apareció originalmente en Los divinos y los humanos, de 1903, publicado en París por Librería Americana. Montoya y Montoya reproduce el texto íntegro con algunas modificaciones tipográficas. En él, Vargas Vila habla de seis lugares que se diferencian por sus características geográficas, históricas y culturales. A Bogotá, tierra de altura, la caracteriza la "imaginación severa y fría”. La identificación, que incluye lo que se da y lo que no - “tierra de estudio más que de genio; de cultivo más que de espontaneidad" (p. 17)—, la concreta la inserción de una figura representativa, que en este caso es Miguel Antonio Caro: "lo clásico mediocre” (p. 18). Vargas Vila procede de igual manera con las cinco regiones restantes: la segunda, "las tierras del Zaque, patria de talentos generosos e inspiraciones bíblicas", allí surge "un don José Joaquín Ortiz, es decir, lo místico sublime” (p. 18); la tercera, “allá en los declives de la Cordillera”, "patria del bocio", donde se dan "imaginaciones enfermas", donde se es un "idiota” y se es parte del "cretinismo literario" representado por "Carlos Martínez Silva, es decir, lo ridículo" (p. 18); la cuarta, "las riberas del mar", ofrece dos tipos de escritores: "Diógenes Arrieta, es decir, lo bello; Rafael Núñez, es decir, lo sombrío” (p. 18); la quinta, el Cauca, es lugar para "un César Conto, es decir, lo fecundo" (p. 19); la sexta y última es Antioquia y con ella se introduce la figura de Juan de Dios Uribe. De Antioquia hay una caracterización a un nivel de influencias y estético. Como influencias se tiene a Camilo Antonio Echeverri, Gutiérrez González y Epifanio Mejía. En lo estético

1 Carrasquilla cita sin nombrarlo al poeta argentino Olegario Víctor Andrade. Los versos pertenecen al poema "La Atlántida. Canto al porvenir de la raza latina en América". 
se resaltan las cualidades del paisaje y el papel de estas en la formación de Uribe: "Su alma se impregnó en la infancia de la majestad de aquellos paisajes retratados en su retina, de aquellos ruidos imponentes que arrullaban sus sueños, de aquella calma sublime que se extendía en torno de él” (p. 19). En consecuencia, de ese ambiente se obtiene "la fuerza de su musculatura y la solidez de su inteligencia" (p. 19). Este ejemplo es significativo porque señala una particularidad importante en la formación de imaginarios, y es que en esta cumplen un papel principal los escritores que ven la región desde afuera y tienen la posibilidad de establecer parámetros de comparación más amplios.

Lo antioqueño también se define por las costumbres, que son de eminente raigambre hispánica. Pero esta raíz no se impone de manera absoluta, sino que al adaptarse al nuevo medio, da lugar a una nueva "estirpe". Es entonces cuando elementos no hispánicos definen parte de la identidad antioqueña, como la alimentación, dentro de la que el maíz, trascendental para las culturas ancestrales de América, se convierte en símbolo de lo antioqueño. Este énfasis en las costumbres, que determina el valor estético de las obras, aparece en la “interpretación biográfica” del indio Uribe que propone Luis López de Mesa (1965):

Los hijos de tales zapadores de selva [los colonizadores antioqueños] no llegaban ciertamente a comer ave fénix empanada, pero al rudo jornal de las dehesas y labrantíos, de los socavones mineros o premiosos quehaceres femeniles, que a nadie, niño siquiera, o mujer, permitiose holganza. Ni qué decir de arriadas y transporte por improvisados caminos y veredas de andurriales a veces, con ríos por medio aturbonados ahí, como el Cauca, o torrentosos y volubles como su acrecido afluente el comarcano San Juan. Y sin embargo de tamaño aislamiento y sumas ocupaciones, en cada hogar se guardase por lectura frecuente no solo obras de devoción como el Año Cristiano de Croisset, estupendamente traducido, o baratura española, con el Quijote a la cabeza, Lope quizás, y de seguro, siempre de seguro, alguna asequible colección de novelas románticas o sabrosas poesías (p. 34).

Un concepto más complejo es la cuestión de la "raza”, en tanto determinación genética. Aunque la palabra "raza” aparece en algunas ocasiones, en pocas designa algo diferente a una comunidad cultural. Sí aparece explícitamente como determinación genética en el prólogo de Luis López de Mesa recién citado. Una de las preocupaciones principales de López de Mesa está en determinar un “derecho de estirpe”, esto es, una descripción genealógica que busca dejar en claro el "limpio abolengo hispánico" de Uribe. Para ello reconstruye el árbol genealógico del Indio hasta llegar a los fundadores de los pueblos de Antioquia, recién llegados de España (López de Mesa, 1965, p. 32). 
Hay un último elemento, quizá el más importante: el carácter universal que alcanza el antioqueño desde su particularidad regional. Lo universal se entiende como el aporte de una cultura particular, desde su definición, a la raigambre que compone la cultura humana en su totalidad. Marcelino Menéndez y Pelayo (1960), en su momento una de las mayores autoridades críticas de la lengua española, anotó acerca de Memoria sobre el cultivo del Maíz en Antioquia: "es, sin duda, lo más americano que hasta ahora ha salido de sus prensas", "si poseyese muchas cosas como este poema, la literatura colombiana sería sin duda la más nacional de América" (p. 75). A propósito del mismo poema, Tomás Carrasquilla (1960) resalta, dentro de este proceso de universalización, la importancia de la traducción y el modo en que las lenguas se definen y adquieren su "característica" a partir de sus poetas:

Antioquia no es nada, como no lo es Toboso, pero ya figura por ahí en los fastos imperecederos de las letras: ya su poema, tan original y todo, ha sido traducido a la lengua de Hugo y de Flaubert. Cualquier día lo será a la de Dante (p. 87).

En síntesis, la literatura antioqueña en Ediciones Académicas abarca textos y autores que recuperaron un imaginario identitario de la élite decimonónica con el que se definió el espacio denominado "Antioquia". Un espacio que no responde a límites políticos o geográficos, sino que delimita una naturaleza, unos símbolos y unas costumbres que la élite de Antioquia definió como "antioqueños". La de Ediciones Académicas es una labor patrimonial de recuperación bibliográfica; las fuentes disponibles no permiten una vinculación política, en sentido partidista. Esta vinculación, sin embargo, no puede descartarse, puesto que el descubrimiento de nuevas fuentes — un archivo personal del editor o de la editorial— podría arrojar luces sobre los propósitos que, por una u otra razón, no era conveniente publicar. La colección se legitima así misma a través de conceptos y críticas positivas de autores consagrados, y a partir del realce continuo de la importancia y canonicidad de los editados. La empresa editorial no se limita a un impacto regional, sino que busca internacionalizar sus autores, lo que se había llevado con algún éxito en años anteriores con Tomás Carrasquilla. Consideramos que la internacionalización de los autores, que se logra con la recepción por parte de autoridades y editoriales extranjeras, es tomada como prueba de consagración y canonización, pues con ello se demuestra que el autor ha logrado en lo particular - la región - lo universal, 
que se alcanza, según el énfasis de la crítica, retratando lo que es esencial y por tanto universal a la condición humana.

Ahora bien, la estética que se percibe en esta crítica no es única del caso antioqueño. Fue, al contrario, un proceso común a otras naciones latinoamericanas. Bernardo Subercaseaux (2007), para el caso de Chile, incluye dentro de "los aspectos que conciernen al espacio y representación de lo nacional" lo que denomina "la estética del rincón”, en la que confluyen elementos estéticos con elementos identitarios:

Mariano Latorre, señaló "ahondar en el rincón es la única manera de ser entendido por el mundo... literariamente la aldea bien descrita es la conquista de lo universal". "Pinta tu aldea y pintaras el mundo" fue consigna estética vigente en la época. Pero el motivo del rincón tiene también el valor de lo propio, implica el supuesto de que existe un específico cultural chileno, y que la literatura debe hacerse cargo de él (p. 282).

El "específico cultural" es el determinante principal del canon de la literatura antioqueña que propone Ediciones Académicas. A partir de la existencia o no de ese elemento, se establece una jerarquía, un nivel de importancia.

\section{Consideración final}

Aun dilucidadas algunas de las estrategias de Ediciones Académicas que le permitieron erigirse como una instancia de conservación de una tradición literaria, quedan muchas preguntas por responder. Una de ellas es el escaso interés editorial que en los últimos años ha habido por sus exponentes. Esto se puede explicar si se tiene presente que "la estética del rincón", la búsqueda de lo universal en lo particular, de lo "específico cultural", de "la Antioquia de nuestros abuelos", al decir de Montoya y Montoya, limita la producción literaria a un naturalismo ciego, entendido como un discurso estético con el referente en un imaginario dado y no en una construcción siempre novedosa que se hace a partir de la experimentación empírica. Olvidado el sustento material que soporta el imaginario — cuya recuperación es labor cultural del Estado y, en menor medida, de la empresa privada, como el caso de Ediciones Académicas-, el referente deja de tener significado. El progresivo desinterés por el libro, que se ha agravado en los últimos sesenta años, ha hecho que este soporte principal de la cultura de la élite decimonónica caiga cada vez más en ese "olvido" tan temido por Montoya y Montoya. "E1 libro no es un asunto relevante en la Colombia contemporánea”, constata Gilberto Loaiza Cano (2016), “desplazado, primero, por la 
radio, la televisión y el cine; luego por el alud de innovaciones de la internet, el libro quedó confinado al raquítico mundo universitario, al consumo oneroso de la clase media urbana culta” (p. 251). Pero la cuestión no es el desplazamiento de soportes en sí, sino el hecho de que junto a este el contenido también cambia. Los imaginarios que transmiten la radio, la televisión y la internet, en un proceso de preservación y legitimación, están lejos del imaginario de las élites decimonónicas antioqueñas; están lejos, incluso, de las élites intelectuales y económicas de Colombia. De ahí que, para un lector culto, que no sea especialista, difícilmente la "literatura antioqueña" pueda ser objeto de interés.

Pese a todo, estas consideraciones no deben ser tomadas como un reproche. Lo que pretendemos es ofrecer una respuesta siempre parcial a la cuestión del olvido y falta de interés por una tradición literaria. Sin duda muchos de los valores que traía consigo ese imaginario decimonónico están hoy día revaluados. El hombre blanco, fuerte, heterosexual, católico, domador de la naturaleza, y la mujer blanca, bella, heterosexual, católica, sumisa, base de la familia y soporte del matrimonio, aparecen hoy chocantes y poco atractivos. Las estructuras sociales han cambiado mucho y las ficciones o imaginarios que las soportan han seguido la misma ruta.

\section{Referencias bibliográficas}

Agudelo Ochoa, A. M. (2015). Devenir escritora: Emergencia y formación de dos narradoras colombianas en el siglo XIX (1840-1870). Lima: Centro de Estudios Literarios Antonio Cornejo Polar.

Carrasquilla, T. (1960). Gregorio Gutiérrez González ante la crítica universal. En R. Montoya y Montoya (Comp.). Obras Completas de Gregorio Gutiérrez González (pp. 85-87). Medellín: Ediciones Académicas.

Carrasquilla, T. (1965). Juan de Dios Uribe. En R. Montoya y Montoya (Ed.). Obras Completas de Juan de Dios Uribe. Tomo I (pp. 9-10). Medellín: Ediciones Académicas.

Chartier, R. (1994). Textos, impresos, lecturas. En Libros, lecturas y lectores en la Edad Moderna (pp. 41-57). Madrid: Alianza Editorial.

Escobar Villegas, J. C. (2009). Progresar y civilizar: imaginarios de identidad y élites intelectuales de Antioquia en Euroamérica, 1830-1920. Medellín: Fondo Editorial Universidad Eafit.

Gutiérrez Panesso, B. A., y Levy, K. (1989). Veinticuatro cartas de Benigno A. Gutiérrez "Cyrano de las letras”. Medellín: Ediciones Gráficas. 
Janik, D. (1998). La literatura en la formación de los estados Hispanoamericanos (1800-1860). Frankfurt am Main: Vervuert Verlag - Iberoamericana.

Loaiza Cano, G. (2016). Premisas para una historia del libro en Colombia. En A. Rubio Hernández (Ed.). Minúscula y plural: cultura escrita en Colombia (pp. 251-270). Medellín: La Carreta Editores. López de Mesa, L. (1965). Juan de Dios Uribe Restrepo (interpretación biográfica en el centenario de su nacimiento). En R. Montoya y Montoya (Ed.). Obras Completas de Juan de Dios Uribe. Tomo I (pp. 32-48). Medellín: Ediciones Académicas.

Martán Góngora, H. (1964). Los poemas desconocidos de Barba Jacob. Boletín Cultural y Bibliográfico 7 (12), pp. 2241-2243.

Menéndez y Pelayo, M. (1960). Gregorio Gutiérrez González ante la crítica universal. En R. Montoya y Montoya (Comp.). Obras Completas de Gregorio Gutiérrez González (pp. 74-75). Medellín: Ediciones Académicas.

Subercaseaux, B. (2007). Literatura, nación y nacionalismo. Arbor: ciencia pensamiento y cultura 183 (724), pp. 277-293.

Tarcus, H. (2016). El socialismo romántico en el Río de la Plata (1837-1852). Buenos Aires: Fondo de Cultura Económica.

Valera, J. (1960). Gregorio Gutiérrez González ante la crítica universal. En R. Montoya y Montoya (Comp.). Obras Completas de Gregorio Gutiérrez González (p. 79). Medellín: Ediciones Académicas. Vargas Vila,J.M. (1965). Juan de Dios Uribe. En R. Montoya y Montoya (Ed.). Obras Completas de Juan de Dios Uribe. Tomo I (pp. 17-23). Medellín: Ediciones Académicas.

Vasco Acosta, J. (2016). Instituciones de la vida literaria y sociedades literarias en Antioquia. Estudio de formas de sociabilidad, 1880-1914 (Tesis doctoral). Bogotá: Universidad de los Andes.

Vivas Hurtado, S. (2015). Komuya uai: Poética ancestral contemporánea. Medellín: GELCIL - Sílaba Editores. Zafir, L. (1960). Sobre el editor. En R. Montoya y Montoya (Ed.). Obras Completas de Gregorio Gutiérrez González (pp. 455-456). Medellín: Ediciones Académicas. 